\title{
A MORTE GALOPA UM CORCEL NEGRO: ALGUMAS APROPRIAÇõeS DE FiLIPE II E ALEXANDRE MAGNO NO SÉCULO XX.
}

\section{Death Rides a Black Horse: some appropriations of Philip II and Alexander the Great in the Twentieth Century.}

La muerte galopa un caballo negro: algunas apropriaciones de Alejandro Magno y Filipo Il en el siglo $X X$.

Thiago do Amaral Biazotto ${ }^{1}$

Resumo: Este texto discute algumas apropriações de Filipe da Macedônia e Alexandre Magno realizadas pelos governos macedônio e grego a partir da segunda metade do século XX. Em particular, debate como estes governos, cada qual a seu modo, se serviram das figuras dos dois soberanos com propósitos nacionalistas.

Palavras-chave: Alexandre Magno (356-323 a.C), Filipe da Macedônia (382-336 a.C.), Arqueologia, Nacionalismo, Tumbas de Vergina.

Abstract: This paper discusses some appropriations of Philip of Macedon and Alexander the Great by Macedonian and Greek governments from the second half of the twentieth century. In particular, discusses who these governments, each in its own way, use the figures of this two monarchs with nationalist purposes.

Keywords: Alexander the Great (356-323 b.C.), Philip of Macedon (382-336 b.C), Archaeology, Nationalism, Vergina Tombs.

Resúmen: Este artículo discute algunas apropriaciones de Filipo de Macedonia y Alejandro Magno realizadas por los gobiernos macedonio y griego en la segunda mitad del siglo XX. En particular, discute como estos gobiernos, cada uno a su manera, han utilizado las figuras de los dos soberanos con fines nacionalistas

Palabras clave: Alejandro Magno (356-323 a.C.), Filipe de Macedonia (382-336 a.C), Arqueología, Nacionalismo, Tumbas de Vergina.

\section{Introdução}

No começo, tudo era caos. Até surgir Gaia, a mãe-terra. A certa altura, ela concebeu aquele que seria seu futuro marido e o transformou em rei. Seu nome era Urano. Com enorme poder, ele criou as montanhas e as nuvens. Arquitetou as raízes dos seres vivos. Teve muitos filhos com sua esposa, os titãs. Entretanto, Urano era cruel, sanguinário, esmagador: baniu seus rebentos para as profundezes do Tártaro. Com o coração ferido diante de tamanho

\footnotetext{
${ }^{1}$ Rua Dr. Francisco de Toledo, no 207 ap. 04, Cidade Universitária, Campinas - SP. CEP 13083-470. (19) 3862-1298. thiago_a_b@yahoo.com.br. Graduado e mestrando em História pela Unicamp. Bolsista de mestrado Fapesp. Orientador: Prof. Dr. Pedro Paulo Abreu Funari.
}

(C) Rev. Arqueologia Pública Campinas, SP v.9 No.(11) p.39-49 suplemento ISSN 2237-8294 
ultraje, o amor materno de Gaia falou mais alto. Junto às crias remanescentes, ela arquitetou uma vingança arrebatadora contra o sádico esposo. Cronos, o caçula, foi voluntário para cumprir a desforra, abatendo seu pai e iniciando uma sina fratricida que resultaria em sua própria morte, tempos depois. Mas esta é outra história. Fato é que os titãs foram resgatados e passaram a governar o mundo, entregando a coroa a Cronos.

O novo soberano possuía muitos irmãos, cada um encarregado de zelar por um atributo específico: Céos era o titã da inteligência. Hiperião, o do fogo. Tétis era a titânide do mar e Mnemósine, a da memória. Ela, Mnemósine, é a mãe das Musas, aquela que sabe o que se passou. Ela, Mnemósine, conhece o aparecimento do mundo, a gênese dos deuses e o nascimento da humanidade. Ela, Mnemósine, garantirá aos deuses a ciência de sua imortalidade e aos mortais reivindicarem origens, traçarem cartografias, desenharam genealogias. Ela, Mnemósine, permitirá aos homens saberem, usarem e abusarem do passado. Possuído pelas Musas, suas filhas, o aedo poderá cantar o passado. Mas o que acontece quando memória e história se misturam? Ou melhor, o que acontece quando o mito divino e o mortal que desejava ultrapassar o mito se juntam? O que acontece quando a memória encontra Alexandre, em um momento no qual a figura do conquistador era usada para fins políticos explícitos?

Instado por tais reflexões, este texto discutirá conceitos como memória e temporalidade, em autores tais como Maurice Halbwachs, Reinhardt Koselleck, Pierre Nora, François Hartog e Fernando Catroga, e articulá-los a um momento especifico: a criação da República da Macedônia, em 1991, momento em que a figura de Alexandre foi resgatada para atender a objetivos políticos.

\section{memória \\ A aurora da nação: o nascimento da República da Macedônia e a disputa pela}

A história dos Bálcãs foi escrita com tintas sangrentas. Perseguições a minorias étnicas, guerras civis e governos autoritários marcam a região. No caso de interesse deste texto, destaque será dado ao nascimento da República da Macedônia, em 1991, num contexto de esfacelamento da República Socialista Federativa da lugoslávia, após a morte do líder Marechal Tito (1892 - 1980). A propósito, é oportuno ressaltar a pluralidade que o termo "Macedônia" pode assumir, de forma a esclarecer o texto. Macedônia tanto pode ser uma expressão genérica para designar a região central dos Bálcãs quanto uma referência à região localizada dentro do território grego e a ele anexada em 1913, pelo tratado de Bucareste. Por fim, usa-se Macedônia para aludir ao Estado independente acima referido. Fica assumido que seu uso aqui assumirá a última conotação.

De certa forma, o esboço da Macedônia como logradouro independente se dá em 1944 quando, em fins da Segunda Grande Guerra, Tito, em conjunto com outros líderes do partido comunista, cria a República Popular da Macedônia. Com a capital fixada em Skopje, o novo território ficou alocado nos limites da antiga lugoslávia até setembro de 1991. Neste ínterim, o desejo pela independência política caminhava lado a lado com o afã por uma anexação de territórios que se encontravam nos limites gregos. Estes territórios seriam habitados por uma 
população cujas raízes étnicas estariam fincadas na Macedônia da Antiguidade, razão pela qual deveriam ser incorporadas a um futuro Estado independente (DANFORTH, 2010: 576). A reação veio de modo semelhante: nacionalistas gregos afirmavam que os macedônios sempre estiveram submetidos à autoridade da Antiga Grécia, de modo que a criação de um Estado autônomo e o desejo de vê-lo povoado pelos helênicos seria uma falácia.

Já aqui podemos traçar pontos de contato com a bibliografia selecionada. Maurice Halbwachs, sociólogo francês de inspiração durkheimiana, contribui com a discussão quando discorre sobre a memória não como um atribuído apenas individual - na contramão de Freud, por exemplo - mas compartilhado por um grupo, dando origem a uma lembrança comum que existe dentro de parâmetros sociais e históricos definidos: "se nossa impressão pode apoiar-se não somente sobre nossa lembrança, mas, também, sobre a dos outros, nossa confiança e exatidão de nossa evocação será maior", escreve o autor (1990: 25). Neste ponto, em Halbwachs, a memória compartilhada cinde-se em dois polos: a memória coletiva, de aspecto espontâneo, apócrifo e não-oficial, e a memória histórica, artificial, vazada em moldes ensináveis e destinada à instrução e recordação. Ela parece ligada a uma tradição oficial, à medida que tem a função precípua de transformar imagens do passado em visões do presente, fazendo, como a Mnemósine mitológica, o esquecido vir à tona. A evocação de uma memória histórica cimentada em um passado compartilhado aparecerá em diversos momentos ao longo deste texto, de vez que tanto o governo macedônio como o grego colocaram-na em suas respectivas agendas.

Estas evocações e apropriações da memória parecem ainda mais cristalinas quando envolvem questões relativas ao nacionalismo, sentimento que, conforme a clássica tese de Hobsbawm, precede até mesmo a formação do Estado Nacional (2008: 18-9). Como é bem sabido, o nacionalismo se alicerça em apanágios como a crença em laços sanguíneos, uma linhagem racial, cultural e linguística unívoca, e, muitas vezes, na existência de um herói pátrio, responsável por encarnar as virtudes de seu povo. Estas seriam as linhas mestras que desenhariam os Estados independentes, cujas fronteiras são traçadas por meio de processo políticos complexos, animados pelas crenças supracitadas, dentro daquilo que foi chamado de "comunidade imaginada", consagrada expressão de Benedict Anderson (2008). No caso macedônio e grego, o "herói nacional" ao qual foi feita referência seria ninguém menos que Alexandre Magno. Por este motivo, o ano de 1977 marca uma inflexão cabal.

\section{Andronikos e as Tumbas de Vergina: lugares de memória e perigos da politização}

Manolis Andronikos foi responsável por uma descoberta que jogaria gasolina na já explosiva fogueira dos nacionalismos. Nascido em 1919, na cidade Bursa, antigo Império Otomano e atual Turquia, Andronikos teve aquilo que hoje se designa pelo quase paleozoico termo de "educação clássica", ou seja, voltada ao estudo das línguas antigas e à leitura de escritores da Antiguidade. Andronikos diplomou-se em Filosofia na Universidade de Tessalônica e obteve doutorado em Oxford, onde estudou sob a tutela do prestigioso Sir John Beazley, retornando à Grécia para tomar assento como professor na Universidade na qual se graduara (ELEZOVIC,

(C) Rev. Arqueologia Pública

\begin{tabular}{l|l} 
Campinas, SP & v.9
\end{tabular}

No.(11)

p.39-49 suplemento

ISSN 2237-8294 
2011: 57-8). Encarregado de dirigir escavações em sítios gregos, o arqueólogo encontrou uma série de tumbas em Vergina, norte helênico, no ano de 1977. A mais suntuosa delas continha um ataúde adornado com uma estrela ou sol de 16 pontas e guardava os ossos que seriam do nobre Filipe II, pai de Alexandre.

De modo sucinto, o arqueólogo atribuiu a tumba a Filipe por tê-la datada de um período entre 350-310 a.C., ocasião na qual apenas dois monarcas macedônios morreram em solo pátrio: o próprio Felipe e Felipe III Arrideu, seu filho, meio irmão de Alexandre e que sofria de graves problemas mentais. Ora, se Arrideu era um reles fantoche, por qual motivo haveria de ser erigido em sua homenagem um sepulcro tão pomposo? Ademais, os ossos encontrados no ataúde estavam queimados, honraria apenas conferida aos mais egrégios monarcas.

Ainda que haja violentas controvérsias a respeito da identificação dos restos mortais para se deter a um breve exemplo, não há qualquer inscrição que nomeie seu dono e mesmo aquele que, de acordo com Andronikos, foi o responsável por sua construção, Alexandre, tinha conturbada relação com seu progenitor, a ponto de, quando da morte de Filipe, seu nome ter sido apontado como um dos mandantes do assassinato (BURSTEIN, 1982: 43-44) Andronikos fez valer o peso de sua autoridade acadêmica e sua interpretação tornou-se a mais corrente ${ }^{2}$.

A argumentação central de Andronikos se encontra no volume Vergina: The Royal Tombs, que, lançado em 1984, contém frases que, decerto, acaloraram o debate em torno das disputas nacionalistas já assinaladas. Vocifera o arqueólogo: "Da forma mais imutável possível, esta evidência confirma a opinião daqueles historiadores que afirmam que os macedônios eram uma tribo grega, como todos os outros que viviam no território grego" (ANDRONIKOS, 1984: 83).

Talvez em função de assertivas como essa, o símbolo encravado no ataúde passou a ser usado pelos nacionalistas helênicos, sob a justificativa de que, sendo a estrela de 16 pontas um distintivo da realeza macedônia e tendo ele sido descoberto em território grego, nada mais normal que afirmar que a Macedônia não passava de um reles pátio da Grécia. Por outro lado, nacionalistas macedônios rebatiam com um argumento que faria até o mais refinado sofista sentir calafrios: se a Macedônia era um grotão grego, por que tardou mais de 2000 anos para que o local do descanso eterno de Filipe II fosse descoberto?

\section{FIGURA 1}

\section{Ataúde encontrado na tumba de Filipe II.}

\footnotetext{
${ }^{2}$ N. G. L. Hammond, historiador britânico que conseguiu a rara proeza de contribuir tanto com a Cambridge Ancient History quanto com o Oxford Classical Dictionar, escreveu, em artigo de 1991, que, ao menos até aquele momento, as conclusões de Andronikos eram irrefragáveis (1991: 82).
} 


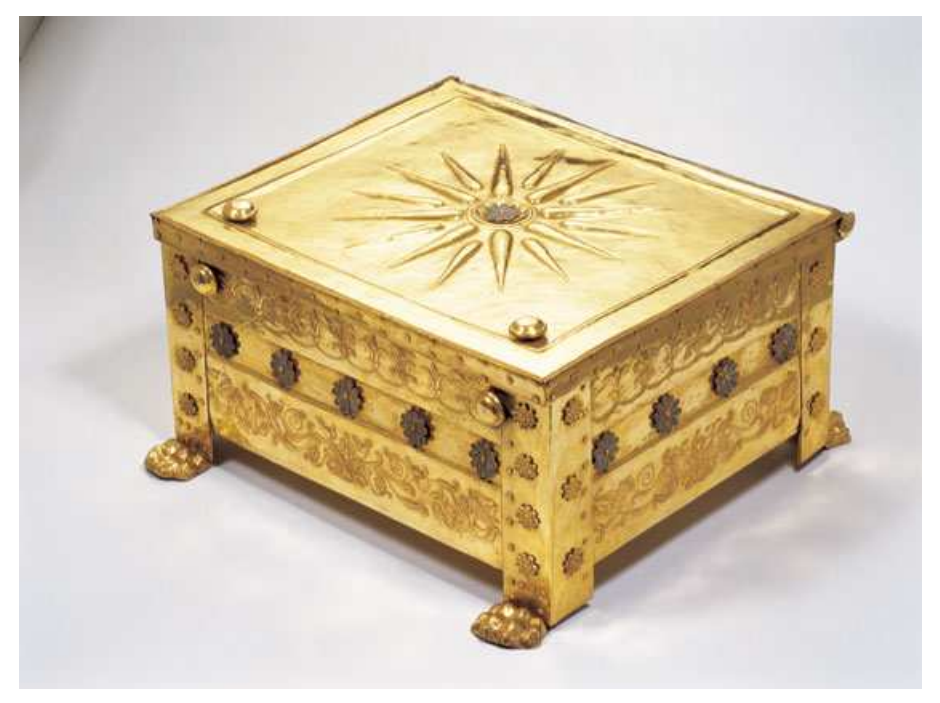

\section{Créditos:}

https://commons.wikimedia.org/wiki/Category:Macedonian_royal_tombs,_Vergina\#/media/File:I mage_larnax_of_philip.jpg (Acesso 25/06/2015).

Seja como for, o governo da Grécia passou a se valer do símbolo de estrela de Vergina. Em 1990, foram cunhadas moedas no valor de 100 drachmas que apresentavam, no anverso, a imagem de Alexandre acompanhada da inscrição "Alexandre, o Grande, rei dos macedônios" (em tradução livre), em clara tentativa tanto de associar a imagem do conquistador à Grécia como, e mais importante, de mostrar como ele, um grego, já era soberano dos macedônios mesmo em tempos de antanho, o que deveria se repetir na contemporaneidade. E qual não é a espécie que nos causa constatar que, no reverso desta moeda, estava estampada a imagem da Estrela de Vergina? (DAHMEN, 2007: 155).

\section{FIGURA 2}

Moeda de 100 dracmas. Grécia, 1990. 

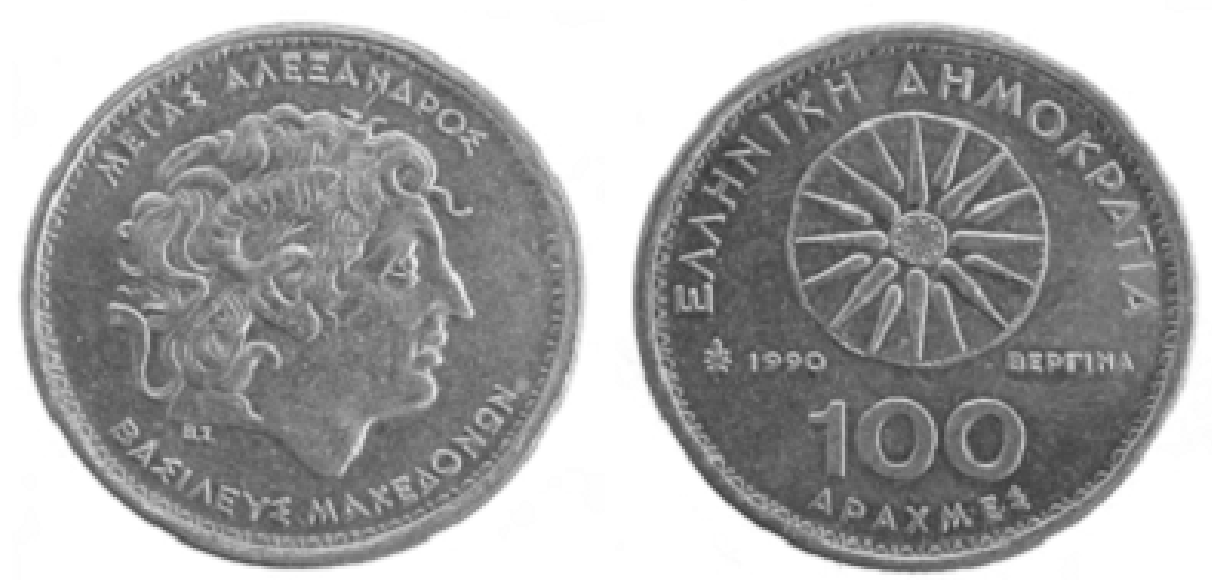

Crédito: DAHMEN, K. The Legend of Alexander the Great on Greek and Roman Coins. New York: Routledge, 2007. P. 155

O contrataque veio, com o perdão do trocadilho, na mesma moeda: em agosto de 1992, o parlamento macedônio definiu que o símbolo de Vergina seria estampado na bandeira do novo país, o que, claro, provocou reações nada diplomáticas dos gregos. Houve quem chamasse a escolha de "um roubo de um símbolo histórico grego", entre outros impropérios (DANFORTH, 2010: 588). Não demorou para que as represálias passassem do âmbito das diatribes para o espectro econômico. Em fevereiro de 1994, os Estados Unidos reconheceram a existência da "Antiga República lugoslava da Macedônia" o que levou os gregos a impor um pesado embargo econômico contra o território recém-reconhecido. Apenas um ano e meio depois é que a desconfortável situação foi resolvida, com a Grécia desfazendo o embargo enquanto a Macedônia se comprometia a retirar a estrela de Vergina de sua bandeira (DANFORTH, 2010: 592).

\section{FIGURA 3}

Bandeira usada pela República da Macedônia, de 1992 a 1995.

\begin{tabular}{|l|l|l|l|l|l|l}
\hline (C Rev. Arqueologia Pública & Campinas, SP & v.9 & No.(11) & p.39-49 & suplemento & ISSN 2237-8294 \\
\hline
\end{tabular}




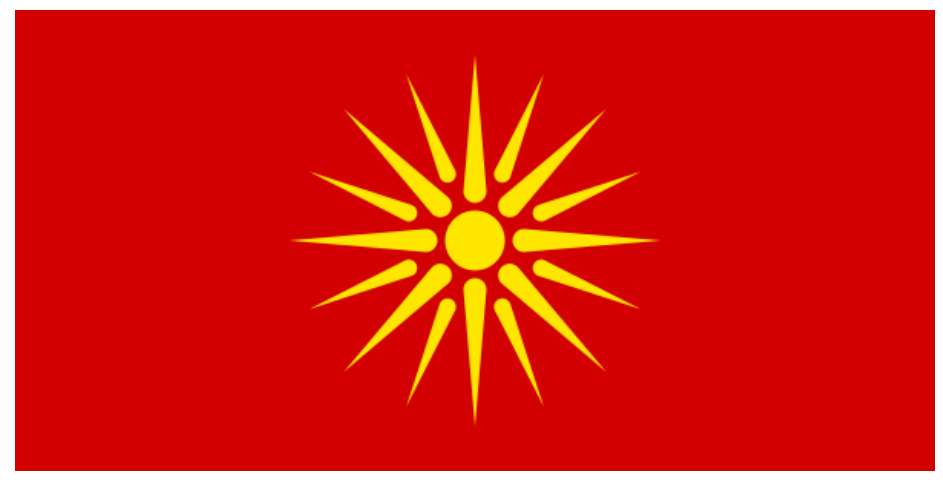

\section{Crédito:}

https://commons.wikimedia.org/wiki/File:Flag_of_the_Republic_of_Macedonia_1992-1995.svg (Acesso 25/06/2015).

Historiador português, Fernando Catroga alerta que a memória "não é um armazém que, por acumulação, recolha todos os acontecimentos vividos pelo indivíduo" (2001: 20), frase que dá novas dimensões às ações dos governos grego e macedônio, que parecem imbuídos do desejo de introjetarem em seus cidadãos memórias oficiais, traduzidas em símbolos que, oriundos da Antiguidade, aludem às questões políticas contemporâneas. Todo este esforço de criação de memórias parece ainda mais peremptório quando o próprio Catroga identifica suas três clivagens: a metamemória, ligada de maneira direta àquilo que o indivíduo viveu, a memória, que se relaciona à dinâmica recordação/esquecimento e, por fim, a protomemória, de caráter mais passivo, e tecida pela socialização, pela convivência. Estes três níveis elucidam as maneiras através das quais os indivíduos se relacionam com seu passado e constroem sua identidade (2001: 15). Se, portanto, parte relevante da identidade é forjada a partir de uma memória construída pela convivência - tanto com grupos, e aqui voltamos a Halbwachs, como com símbolos - as iniciativas grega e macedônia parecem ganhar novas dimensões.

Já Pierre Nora, no texto "Entre memória e história: a problemática dos lugares", delineia o conceito de "lugares de memória", salutar pra este texto. Nora identifica, em finais do século XX, uma "morte" da memória, de vez que ela foi historicizada - num eufemismo para domada. Tal se dá pelo fato de a História se pretender científica, fria e universal, aspectos diametralmente opostos aos apanágios da memória (1993: 9). Diante disto, o autor percebe, no momento em que escreve, 1984, a era dos lugares de memórias: espaços de celebração, de lembrança, rincões privilegiados de comemoração, (1993: 27). À luz das formulações de Nora, é possível perceber certo uso do expediente dos lugares de memórias tanto pelos gregos quanto pelos macedônios. A própria Tumba de Vergina seria um exemplo - e, neste caso, somos seduzidos a crer que a iniciativa foi bem-sucedida, quando se recorda que o local foi tomado como patrimônio pela UNESCO e recebe cerca de 300.000 visitantes ao ano (ELEZOVIC, 2011: 55). 
Contudo, a criação ou restauro de lugares de memória não se limita ao local de descanso do caolho Filipe. Outro exemplo é a incensada acrópole de Atenas, que fora devidamente "limpa" de artefatos otomanos indesejados, classificados como "reminiscências de barbarismo" por Leo Von Klenze, arquiteto encarregado da restauração do Partenon durante das décadas de 1830 e 1840, logo após a separação da Grécia do Império Otomano (MACKRIDGE, 2008: 305).

Se a tal "limpeza" não foi feita dentro do período primacial dos lugares de memória identificado por Nora, ela situa em temporalidade bastante relevante tanto para François Hartog quanto para Reinhardt Koselleck. Ambos percebem, na virada do século XVIII para o XIX, mudanças significativas dentro das formas através das quais a sociedade ocidental articulava suas noções de tempo. Em Koselleck, para quem a experiência de tempo ocidental pode ser traduzida nos termos de "espaço de experiência" - circunscrito, voltado ao passado e dentro do qual os acontecimentos podem ser lembrados - e de "horizonte de expectativa" - amplo, tornado ao futuro, quando o porvir vale mais do que aquilo que se passou (2006: 309-11) - vê na viragem mencionada o momento em que o último sobrepujou o primeiro, quando a perspectiva do futuro passou a ser maior que a preocupação com as raízes de um passado do qual se poderia aferir ensinamentos valiosos. Hartog assinala movimento semelhante dentro daquilo chamado de "regime de historicidade", ferramenta heurística usada para medir: "a maneira de engrenar passado, presente e futuro ou de compor um misto das três categorias (...) a maneira como um indivíduo ou uma coletividade se instaura e se desenvolve no tempo" (2013: 11-13). Segundo o historiador francês, as décadas terminais do século XVIII assistem à mudança do antigo regime de historicidade, guiado pela crença na história magistra vitae, caracterizado pela convicção de que era necessário aprender com o passado, para um regime moderno, cuja marcada são os olhos voltados ao futuro, à aceleração do tempo e ao progresso, (HARTOG, 2013: 10). A reconstrução da Acrópole, portanto, pode ser vista como um pequeno ponto fora da curva, em uma espécie de momento transitório entre dois regimes de historicidade.

Mas, voltado aos lugares de memória, é oportuno lembrar que, em 1992, cerca de um ano após a criação da República Macedônia, o governo grego achou por bem mudar os nomes dos aeroportos de Tessalônica e Kavala para "Aeroporto Macedônia" e "Aeroporto Alexandre, o Grande", em clara provocação. Em atitude semelhante, a Macedônia alterou para "Alexandre, o Grande" o nome do principal aeroporto de Skopje, em 2006 (DANFORTH, 2010: 538). Também exemplo gritante desta corrida por uma "antiquização" da Grécia e da Macedônia foi a construção de uma imensa estátua em bronze de Alexandre, disposta em Skopje, de custo estimado foi de 4,5 milhões de euros. O monumento não poderia ter sido inaugurado em data mais sintomática: 2011, exatos 20 anos após a criação da Macedônia independente.

Curioso notar como o mesmo expediente já havia sido utilizado pelos gregos, que, em 1974, erigiram outro monumento em homenagem ao conquistador, na cidade de Tessalônica aliás, bastante semelhante à versão criada pelos macedônios, tempos depois. Como se vê, a disputa pela memória também se espraia para a disputa pelos lugares de memória.

(C) Rev. Arqueologia Pública

\begin{tabular}{l|l} 
Campinas, SP & v.9
\end{tabular}

No.(11) p.39-49 suplemento 
Entretanto, nada é mais dantesco que o plano de um endinheirado grupo de greco-americanos que ambicionava investir suas polpudas contas bancárias na construção de algo como um caricatura lítica do famoso monte Rushmore, substituindo os conhecidos semblantes dos presidentes Washington, Jefferson, Roosevelt e Lincoln pelo de Alexandre ${ }^{3}$. A "homenagem" ao conquistador custaria apenas algo da cifra de 30 milhões de euros e teria em torno de 70 metros de altura (DANFORTH, 2010: 584).

Ainda em diálogo com Pierre Nora, outra expressão usada pelo francês é dos perigos da "politização" da História, aspecto que também aparece no objeto de interesse deste texto. Nora acredita que, ao longo das últimas três décadas, os historiadores têm se envolvido cada vez mais em questões relativas ao presente, como as consequências do colonialismo, o que influencia em suas elucubrações sobre o passado. Sendo assim, os atuais historiadores, não raro, se veem acossados por vicissitudes do presente e por elas são influenciados, redundando em maiores preocupações a respeito de seu papel como figuras públicas (NORA, 2011: 9-10).

Neste caso, exemplo digno de nota é carta redigida pelo professor de Arqueologia Clássica da Universidade de Berkley, Stephen Miller, e subescrita por outros tantos catedráticos, e endereçada a outro senão o próprio Barack Obama na tentativa, um tanto quixotesca, diga-se, de sensibilizá-lo frente às hediondas apropriações que são feitas pelos macedônios da mais ínclita figura da Grécia, Alexandre ${ }^{4}$. Para além de certa falta de autocrítica - como visto, os gregos também se apropriam da imagem do conquistador - fica míster um caso visível de politização da História, conforme Nora alerta em seus escritos.

\section{Considerações finais}

Foi o objetivo deste texto discutir como as noções de nacionalismo e memória se articulam, usando como exemplo o conflito entre gregos e macedônios por suas identidades, territórios, bem como disputas por símbolos e figuras históricas, em especial as de Alexandre e Felipe II. Se, como assevera Halbwachs, há tantas memórias quantos grupos existentes, não parece ser falacioso admitir a possibilidade da existência de altercações quando dois grupos competem, ao menos segundo seus próprios pontos de vista, pelas mesmas memórias. Ademais, viu-se como esta disputa extrapola para os lugares de memória, numa corrida desenfreada pela construção e restauro de monumentos que aludem às figuras históricas supracitadas.

Isto posto, também foi discutido o conceito de politização da História, nos termos de Nora, que aparece de forma assertiva quando acadêmicos diversos escrevem - sabe-se lá sob quais constrangimentos - missivas em favor deste ou daquele grupo. Nesta ordem de ideias, talvez o último e mais gritante exemplo seja mesmo o de Manolis Andronikos. Responsável pela escavação da Tumba de Felipe II e por opiniões bastante contundentes a respeito do local da
${ }^{3} \mathrm{~A} \quad$ notícia
da construção
está
disponível
no
seguinte
link:
http://news.bbc.co.uk/2/hi/europe/2210108.stm. Acesso: 01/07/2014.
${ }^{4} \mathrm{~A}$ epístola pode ler lista no seguinte link: http://macedonia-evidence.org/obama-letter.html. Acesso: 01/07/2014. Não há notícia de que Obama tenha dado qualquer atenção à missiva. 
Macedônia como uma província grega limítrofe, o arqueólogo foi laureado em 1992 - portanto, nos píncaros do conflito greco-macedônio - com a Grande Cruz da Ordem da Fênix, mais prestigiosa condecoração cedida pelo governo da Grécia a civis. Ademais, Andronikos foi descrito no ato da premiação como um "arqueólogo nacional" que sempre empunha "o arco do helenismo", em qualificação tão cafona quanto sintomática (DANFORTH, 2010: 588). Nesta mesma época, não era raro encontrar transeuntes desfilando camisetas com mensagens da estirpe de "Primeiro aprenda História" - metonímia para "primeiro aprenda a verdade" e "O espírito de Alexandre, o Grande é universal, mas sua terra-natal, a Macedônia, tem sido grega pelos últimos 3000 anos" (WHITMARSH, 2002: 174). Com tais exemplos em linha de conta, não é de se desprezar a máxima de Liakos que sentencia "a historiografia grega é um produto do Estado Nacional Grego" (2008: 204). O contraponto é tocado por Brunnbauer (2003-4): "desde o começo, em finais da década de 1940, a historiografia macedônia tinha e continua tendo uma explícita perspectiva nacional".

\section{Referências bibliográficas}

ANDERSON, B. Comunidades imaginadas: reflexões sobre a origem e a difusão do nacionalismo. São Paulo: Companhia das Letras, 2008.

ANDRONIKOS, M. Vergina: The Royal Tombs and the Ancient City. Ekdotike Athenon S.A., Athens, 1984.

BRUNNBAUER, V. Serving the Nation: Historiography in the Republic of Macedonia (FYROM) after Socialism. In Historien, vol. 4, 2003-4, pp. 161-182.

BURSTEIN, S. The Tomb of Philip II and the Succession of Alexander the Great. In: Echos Du Monde Classique/Classical Views, vol. 26, 1982, pp. 141 - 163.

CATROGA, F. Memória, história e historiografia. Coimbra: Quarteto, 2001.

DAHMEN, K. The Legend of Alexander the Great on Greek and Roman Coins. New York: Routledge, 2007.

DANFORTH, L. Ancient Macedonia, Alexander the Great and the Star or Sun of Vergina: National Symbols and the Conflict between Greece and the Republic of Macedonia. In ROISMAN, J. \& WORTHINGTON, I. A companion to Ancient Macedonia. Oxford: Blackwell, 2010, pp. 572-598.

ELEZOVIC, A. Manolis Andronikos: Greece's National Archaeologist. Clio's Purple and Gold, Vol. 1, 2011, pp. 54-66.

HALBWACHS, M. A memória coletiva. São Paulo: Vértice, 1990.

HAMMOND, N. The Royal Tombs at Vergina: Evolution and Identities. The Annual of the British School at Athens, vol. 86, 1991, pp. 69-82. 
HARTOG, F. Regimes de Historicidade. Presentismo e Experiências do Tempo. Belo Horizonte: Editora Autêntica, 2013.

HOBSBAWM, E. J. Nações e nacionalismo desde 1780: programa, mito e realidade. Rio de Janeiro: Paz e Terra, 2008.

KOSELLECK, R. Futuro Passado. São Paulo: Contraponto, 2006.

LIAKOS, A. Hellenism and the making of Modern Greece. In ZACHARIA, K. (ed.). Hellenisms: culture, identity, and ethnicity from antiquity to modernity. Aldershot, England; Burlington: Ashgate, 2008.

MACKRIDGE, P. Cultural Difference as National Identity of Modern Greece. In ZACHARIA, K. (ed.). Hellenisms: culture, identity, and ethnicity from antiquity to modernity. Aldershot, England; Burlington: Ashgate, 2008.

NORA, P. Recent history and the new dangers of politization. In Eurozine, 24/11/2011. Disponível em: http://www.eurozine.com/articles/2011-11-24-nora-en.html. Acesso: 03/07/2014.

NORA, P. Entre memória e história: a problemática dos lugares. In. Projeto História, São Paulo (10), 1993, pp. 7-29 (Originalmente in: Les Lieux de memórie, pp. XVIII-XLII. Trad. Yara Aun Khoury)

WHITMARSH, T. Alexander's Hellenism and Plutarch's Textualism. In: The Classical Quarterly. New Series, Vol. 52, № 1, 2002, pp. 174-192.

\begin{tabular}{|l|l|l|l|l|l|l}
\hline (C Rev. Arqueologia Pública & Campinas, SP & v.9 & No.(11) & p.39-49 & suplemento & ISSN 2237-8294 \\
\hline
\end{tabular}

